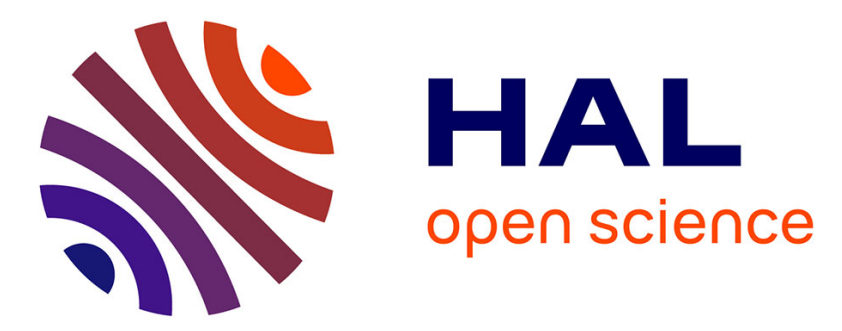

\title{
Unexpected disruption of the dimensionality-driven two-photon absorption enhancement within a multipolar polypyridyl ruthenium complex series
}

Nicolas Durand, Rana Mhanna, Paul Savel, Huriye Akdas-Kiliç, Jean-Pierre Malval, Olivier Soppera, Jean-Luc Fillaut

\section{To cite this version:}

Nicolas Durand, Rana Mhanna, Paul Savel, Huriye Akdas-Kiliç, Jean-Pierre Malval, et al.. Unexpected disruption of the dimensionality-driven two-photon absorption enhancement within a multipolar polypyridyl ruthenium complex series. Chemical Communications, 2020, 56 (84), pp.12801-12804. $10.1039 / \mathrm{d} 0 \mathrm{cc} 05025 \mathrm{c}$. hal-02959812

\section{HAL Id: hal-02959812 \\ https://hal.science/hal-02959812}

Submitted on 19 Oct 2020

HAL is a multi-disciplinary open access archive for the deposit and dissemination of scientific research documents, whether they are published or not. The documents may come from teaching and research institutions in France or abroad, or from public or private research centers.
L'archive ouverte pluridisciplinaire HAL, est destinée au dépôt et à la diffusion de documents scientifiques de niveau recherche, publiés ou non, émanant des établissements d'enseignement et de recherche français ou étrangers, des laboratoires publics ou privés. 


\section{Graphical Abstract.}

The dimensionality-induced two-photon absorption enhancement is rationalized within a multipolar Ru-complexes series with an unexpected disruptive effect emerging from inter-branch 'anti-cooperative' couplings.

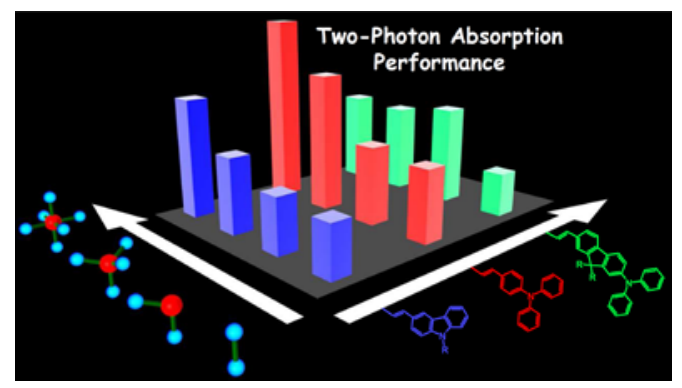




\section{Unexpected Disruption of the Dimensionality-driven Two-Photon Absorption Enhancement within a Multipolar Polypyridyl Ruthenium Complexes Series.}

Nicolas Durand ${ }^{1}$, Rana Mhanna ${ }^{2}$, Paul Savel ${ }^{1}$, Huriye Akdas-Kiliç ${ }^{1,3}$, Jean-Pierre Malval ${ }^{* 2}$, Olivier Soppera ${ }^{2}$, Jean-Luc Fillaut ${ }^{* 1}$.

\footnotetext{
${ }_{1}^{1}$ Université Rennes, Institut des Sciences Chimiques de Rennes CNRS UMR 6226, F-35000 Rennes.

2 Institut de Science des Matériaux de Mulhouse CNRS-UMR 7361, Université de Haute Alsace, 15 rue Jean Starcky, 68057, Mulhouse, France.

3 Yildiz Technical University, Department of Chemistry, 34220 Esenler, Istanbul, Turkey.
}

E-Mails: jean-luc.fillaut@ univ-rennes1.fr and jean-pierre.malval@uha.fr

The dimensionality-driven two-photon absorption (2PA) enhancement effect is investigated in a series of functionalized bipyridyl Ru-complexes. Our design strategy leads to very high 2PA responses up to $\sim 1500 \mathrm{GM}$. However, we highlight that the 2PA performance vs. dimensionality correlation reaches an unexpected limit stemming from 'anti-cooperative' interchromophoric couplings.

Molecules with optimized 2PA efficiency are highly demanded in the fields of photonics and biology ${ }^{1}$. Indeed, 2PA materials are extensively widespread across many applications including microfabrication ${ }^{2}$, high density data storage $^{3,} 4$, bio-imaging ${ }^{5-7}$ or photodynamic therapy ${ }^{8}$. Several critical factors determine the 2PA performances of full organic systems : the symmetry of the structure, the extent of the $\pi$-conjugation length, the occurrence of an efficient intramolecular charge transfer (ICT) both modulated by the nature and the position of electron donor and acceptor groups within the designed molecule? . Alternatively, coordination chemistry offers a versatile strategy for designing two-photon absorbers whose NLO properties are associated to charge-transfer processes such as intraligand charge-transfer (ILCT) and metal-ligand charge-transfer $(\mathrm{MLCT})^{10-13}$. The metal center acts as a powerful template for self-organizing 2PA chromophores in a three-dimensional arrangement ${ }^{9,}{ }^{14}$. Very high 2PA amplifications can then be observed due to the synergistic interplay and extent of electronic couplings between the organic branches ${ }^{15}$. In line with this strategy, we designed a series of homoleptic and heteroleptic $\left[\operatorname{RuL}_{n}(\text { bpy })_{3-n}\right]^{2+}(n=1$, $2,3)$ complexes whose geometrical structuration accounts for two main objectives : (i) Quantifying the 2PA enhancement upon a methodical
Electronic Supplementary Information (ESI) available: Additional figures and tables. Experimental procedures. Synthesis and characterization of new compounds

change of the ligand conjugation length and the complex coordination number, n. (ii) Identifying the cooperative and/or 'anti-cooperative' electronic interactions emerging from this incremental metal-template building strategy. With this respect, we have designed several 2,2'-bipyridinebased ligands which are 4,4'-substituted by distinctive electron-rich arylamine groups such as triphenylamine (T), carbazolyl (C) and diphenylaminofluorenyl (F) subunits through a vinylene linker (Scheme 1). These peripheral $\pi$ conjugated subunits have been selected since their electron-donor ability as well as their $\pi$-conjugation length can be regulated through a planarization effect. Such a structural constraint together with the progressive increase of 3D-dimensionality will give rise to competing interactions between 'through-bond' and 'through-space' couplings ${ }^{16,17}$ within the complexes series leading to a severe disruption in the dimensionality-induced 2PA enhancement effect.

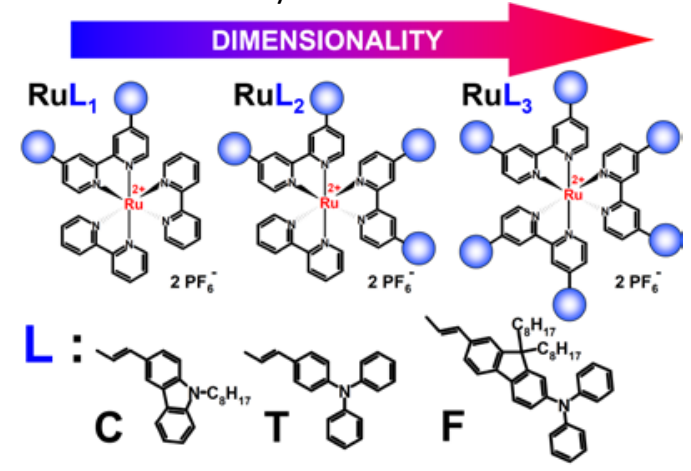

Scheme 1. Molecular structures of the Ru-complexes.

The absorption spectra of the ligands along with their corresponding Ru-complexes in tetrahydrofuran (THF) are shown in Figure 1. The absorption of $\mathrm{Ru}(\mathrm{bpy})_{3}{ }^{2+}$ used as a reference complex is also displayed. The spectroscopic data are summarized in Table $\mathbf{1}$. All the ligands present similar spectral features particularly with the presence of a longest wavelength absorption band located in the $330-450 \mathrm{~nm}$ range. This band is mainly dominated by the $\mathrm{S}_{0} \rightarrow \mathrm{S}_{1}$ electronic transition which implies a long range electronic 
delocalization within the $\pi$-conjugated structure with a significant ICT character from the peripheral donor amino groups to the central acceptor bipyridine moiety ${ }^{12,18}$. This CT band is both sensitive to the nature of the donor subunit and the conjugation length. For instance, the better donor ability of the triphenylamine moiety as compared to the carbazole one $^{19,20}$ leads to a clear bathochromic effect on going from $\mathbf{C}$ to $\mathbf{T}$. Moreover, such a CT process is all the more amplified when considering the dipole moment change between the ground and the excited emitting state.

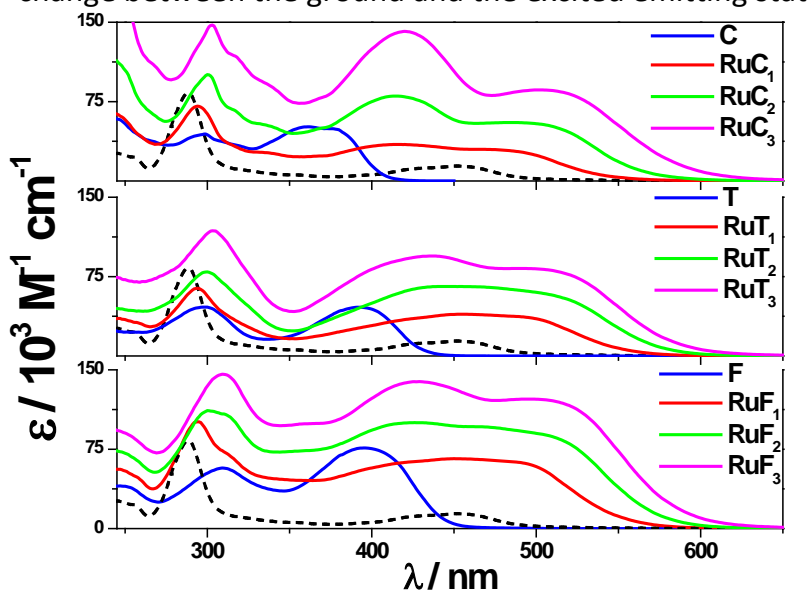

Fig.1 Absorption spectra (full lines) of the ligands and their corresponding Ru-complexes in THF. Dashed lines: Absorption spectrum of $\mathrm{Ru}(\mathrm{bpy})_{3}{ }^{2+}$ in acetonitrile.

As shown in Figures S1-S3, all the ligands are fluorescent and undergo very large amplitude Stokes shifts up to one order of magnitude on going from apolar to highly polar solvents. Based on these solvatochromic measurements, the dipole moment change between ground and relaxed excited state $\left(\Delta \mu_{01}\right)$ has been estimated using LippertMataga formalism ${ }^{21}, 22$ (see Figure S4 and Table S1). Therefore, we show that all the ligands display very high $\Delta \mu_{01}$ with values of $13.6 \mathrm{D}$ for $\mathrm{C}, 18.5 \mathrm{D}$ for $\mathrm{T}$, and $27.9 \mathrm{D}$ for F. Note that $\Delta \mu_{01}$ is multiplied by a factor 2 between $\mathbf{C}$ and $\mathbf{F}$ which confirms the very strong ICT enhancement promoted by our proposed structural changes. Analogously, the coordination to $\mathrm{Ru}^{2+}$ strongly influences the ligands absorption spectra (Figure 1). All the metal-complexes display a well distinctive band in the $270-320 \mathrm{~nm}$ range similarly to that observed for $\mathrm{Ru}(\mathrm{bpy})_{3}{ }^{2+}$. This band presumably corresponds to the ligand-centred (LC) $\pi \rightarrow \pi^{*}$ transitions ${ }^{23}$ (bipyridine-centred transitions). Note that this LC band shifts to the red region and increases in intensity with the coordination number of functionalized-bipyridyl ligands ( $n$ ). Similar effects can be observed when considering the lowest energy band which progressively developed in the 350-630 $\mathrm{nm}$ range. This very broad and structured band encompasses several electronic transitions ${ }^{10,}{ }^{12}$ : the intraligand charge transfer (ILCT) transitions and the metal-to-ligand charge transfer (MLCT) ones. The ILCT band is located at the blue side of the lowest energy band and increases in intensity with $\mathrm{n}$.

\begin{tabular}{clccc}
\hline & $\begin{array}{l}\lambda_{I P A}\left(\varepsilon_{a b s}\right) \\
/ \mathrm{nm}\left(10^{3} \mathrm{M}^{-1} \mathrm{~cm}^{-1}\right)\end{array}$ & $\begin{array}{c}\lambda_{2 P A} \\
/ \mathrm{nm}\end{array}$ & $\begin{array}{c}\delta_{\mathrm{MAX}} \\
/ \mathrm{GM}\end{array}$ & $\begin{array}{c}\delta_{\mathrm{MAX}} / \mathrm{N}_{\text {eff. }}{ }^{2} \\
/ \mathrm{GM}\end{array}$ \\
\hline $\mathbf{C}$ & $362(51)$ & 705 & 200 & 0.25 \\
$\mathbf{R u C}_{\mathbf{1}}$ & $415(34.5), 469(29.9)$ & 795 & 395 & 0.27 \\
$\mathbf{R u C}_{\mathbf{2}}$ & $415(80.2), 485(55.2)$ & 840 & 655 & 0.37 \\
$\mathbf{R u C}_{3}$ & $420(141.4), 503(86.1)$ & 855 & 1381 & 0.58 \\
& & & & \\
$\mathbf{T}$ & $392(46.1)$ & 780 & 187 & 0.35 \\
$\mathbf{R u T}_{\mathbf{1}}$ & $455(39.5), 489(37.3)$ & 855 & 311 & 0.38 \\
$\mathbf{R u T}_{\mathbf{2}}$ & $445(65.7), 505(58.9)$ & 855 & 822 & 0.67 \\
$\mathbf{R u T}_{3}$ & $437(94.5), 504(82.0)$ & 855 & 1465 & 0.91 \\
& & & & \\
$\mathbf{F}_{\mathbf{R u F}}$ & $395(76.2)$ & 800 & 208 & 0.22 \\
$\mathbf{R u F}_{\mathbf{2}}$ & $426(66), 493(61.7)$ & 855 & 596 & 0.48 \\
$\mathbf{R u F}_{\mathbf{3}}$ & $429(138.9), 502(122.1)$ & 870 & 1315 & 0.46 \\
\hline
\end{tabular}

Table. 1 1PA and 2PA properties of the ligands and Ru-complexes (Solvent : THF). The experimental uncertainty for $\delta$ is $\pm 15 \%$.

When comparing the free ligand to its first heteroleptic complex, the ICT band clearly redshifts in concomitance with a substantial decrease in intensity. Whereas this bathochromic effect can be confidently attributed to the electron withdrawing exaltation of the branched bipyridine coordinated to $\mathrm{Ru}^{2+}$, the observed band decrease should be ascribed to a severe reduction of the conjugation length within the entire structure of the ligand probably due to a loss in planarity of the 2,2'-bipyridine which undergoes a trans-to-cis conformation change upon complexation. The MLCT bands which strongly overlap with the ILCT ones are typically positioned at the low energy side of the complexes absorption band. For all the heteroleptic complexes, two distinctive MLCT transitions can be observed due to the presence of two types of bipyridine ligands: i) The $d \pi(\mathrm{Ru}) \rightarrow$ $\pi^{*}$ (bpy) transitions are presumably located in the $430-460$ $\mathrm{nm}$ range as suggested by the MLCT band of Ru(bpy) ${ }_{3}{ }^{2+}$ (see Figure 1). This band has a moderate intensity $\left(\varepsilon_{\text {MAX }} \sim 14000\right.$ $\mathrm{M}^{-1} \mathrm{~cm}^{-1}$ ) and can be distinguished on the structured absorption band of the heteroleptic complexes. ii) The $\mathrm{d} \pi(\mathrm{Ru}) \rightarrow \pi^{*}$ (bpy-substituted) transitions should correspond to the broad and intensive band at the red edge of the absorption spectrum. This red-shifted MLCT band grows incrementally with $\mathrm{n}$ in the same manner as for the ILCT band. The luminescence properties of the metalcomplexes in THF are presented in Figure $\mathbf{5} 5$ and in Table S2. All the complexes are weakly emissive with a luminescence quantum yield $\left(\Phi_{L}\right)$ lower than $10^{-2}$ in nondegassed THF. The luminescence is very sensitive to oxygen with values of $\Phi_{L}$ enhanced by factor $\sim 10$ when operating in $\mathrm{N}_{2}$-saturated THF. This is an indication that the 
luminescence of the complexes arises from the triplet ${ }^{3} \mathrm{MLCT}$ state. It is noteworthy that the luminescence bands are strongly redshifted with respect to that of $\mathrm{Ru}(\mathrm{bpy})_{3}{ }^{2+}$. This clearly underlines the electronic effect of the bipyridine functionalization. Indeed, the 4, 4'-substitution of bipyridine with electron donating groups stabilizes the ${ }^{3}$ MLCT state ${ }^{24,25}$. This electronic configuration implies a drift of electron density from the metal to the ligands with a dominant electronic localization on the substituted bipyridines. This assumption is both consistent with the observed luminescence spectral changes and the strong stabilization of the ${ }^{3} \mathrm{MLCT}$ state energy $(\Delta \mathrm{E}=0.18-0.26 \mathrm{eV})$ as compared to $\mathrm{Ru}(\mathrm{bpy})_{3}{ }^{2+}$. Increasing the dimensionality of the complex with functionalized bipyridines also induces a 3-fold enhancement of the complexes emissivity (see Table S2). This luminescence 'switch-on' of the 3D complexes presumably stems from a shielding effect of the peripheral donor branches from the dynamic oxygen quenching.

Increasing the dimensionality of metal-complexes also impacts the 2PA properties. Figure 2 shows 2PA spectra of the metal-complexes in THF, alongside the corresponding one-photon absorption (1PA) spectra. Figure S6 also presents the 1PA and 2PA spectra of the ligands in THF. According to our spectral resolution, the ligands display a 2PA band in the $700-900 \mathrm{~nm}$ range which reasonably matches their respective lowest energy 1PA band. However, the 2PA cross-sections are moderate for all ligands with $\delta_{\text {MAX }}$ hardly reaching $~ 200 \mathrm{GM}$ whatever the conjugation length or the donor group nature (see Table 1). Such modest values presumably originate from the very close centrosymmetric geometry of the ligands (i.e. D- $\pi$-A$\pi-D)$ leading to a theoretically two-photon forbidden character of the $\mathrm{S}_{0} \rightarrow \mathrm{S}_{1}$ transition. By contrast, the complexation with $\mathrm{Ru}^{2+}$ induces a very strong amplification of the 2PA cross-sections by more than a factor 6 between the free ligands and their respective homoleptic complexes. Moreover, increasing the number of $\pi$-functionalized bipyridines gives rise to very high $\delta_{\text {MAX }}$ up to $1465 \pm 220 \mathrm{GM}$ for $\mathbf{R u T}_{3}$. Such a strong 2PA enhancement proceeds through a synergy effect which combines an effective increase of the intramolecular charge transfer per branch and the cooperative interbranch coupling within the entire multipolar structure ${ }^{13,26}$. As illustrated in Figure 2, the 2PA spectra of all the complexes feature a very intensive band which nicely coincides with the ILCT transitions and a second 2PA resonance in the lowest energy region which matches the MLCT transitions. However, the evolution of the relative intensities of these two bands all along our complexes series suggests that the MLCT resonance increases to the detriment of the ILCT one especially for the $\mathbf{F}$ series. Of particular interest, the ILCT-to-MLCT band ratio undergoes very strong changes which both depend on the coordination number and the nature of the ligand. For instance, this ratio is about $\sim 8$ for $\mathbf{R u C}_{3}$ but progressively decreases to 3.6 and 1.9 for $\mathbf{R u T}_{3}$ and $\mathbf{R u F}_{3}$ respectively.

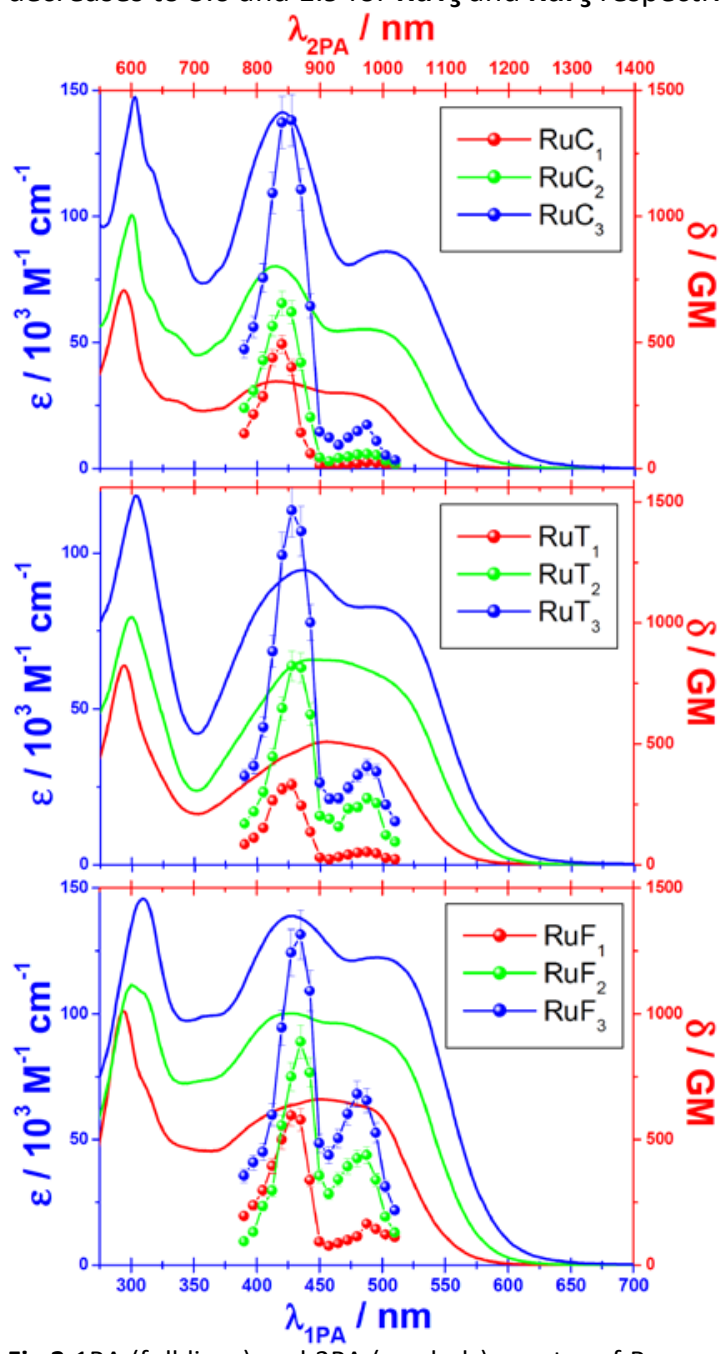

Fig.2 1PA (full lines) and 2PA (symbols) spectra of Ru-complexes in THF. The one-photon molar absorption is shown at the 1PA wavelength (lower horizontal scale). The 2PA cross section is shown as a function of the excitation laser wavelength (upper horizontal scale).

Such a monotone spectral effect from $\mathbf{C}$ to $\mathbf{F}$ series illustrates the increase of dipole-dipole interchromophoric couplings $^{16}$. However, in the present case, the magnitude and the orientation of the interbranch cross-talk within the complexes give rise to an unexpected disruptive effect of the 2PA enhancement course with dimensionality. In order to quantify such a disruption, one should first consider that $\delta_{\text {MAX }}$ increases quadratically with the effective number of $\pi$ electrons $\left(N_{\text {eff }}\right)$ contributing to the nonlinear response ${ }^{27,28}$. Therefore, $\delta_{\text {MAX }}$ has been normalized by $\mathrm{N}_{\text {eff }}{ }^{2}$ in order to access to the intrinsic 2PA cross-section which indeed accounts for the real 2PA performance of a dye. For determining $\mathrm{N}_{\text {eff, }}$, we used the relevant counting method 
proposed by Kuzyk et $a l^{27,28}$ which consists in calculating $\mathrm{N}_{\text {eff }}$ by geometrically weighting the number of electrons in each conjugated path of the molecular system. According to this methodology, Figure $\mathbf{3}$ shows a histogram showing the 2PA performance of all the chromophores as a function of the ligands conjugation length and the coordination number. Note that these two coordinates respectively depict the 'through-bond' (via conjugation) and 'through-

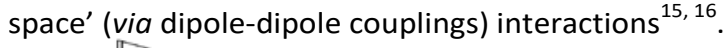

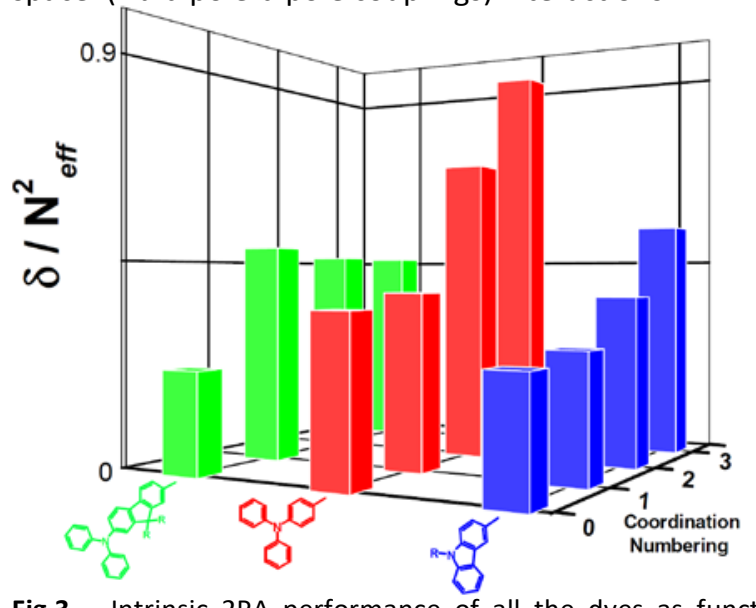

Fig.3 Intrinsic 2PA performance of all the dyes as function of ligands $\pi$-conjugation length and complexes coordination number.

According to this methodology, it can be inferred that the triphenylamine series exhibits the optimal behaviour in term of 2PA cooperative effect. Indeed, $\delta / \mathrm{N}_{\text {eff }}{ }^{2}$ increases gradually with the coordination number (n) and $\mathbf{R u T}_{\mathbf{3}}$ exhibits the highest 2PA performance amongst its homologues. The 2PA performance of the carbazole series presents a similar behaviour but with a much weaker 2PA amplification. Finally, one of the most striking results concerns the diphenylaminofluorenyl series whose 2PA performance rapidly saturates for $n=2$ and 3 . Even though RuF $_{1}$ constitutes the most promising 2PA active candidate as compared to $\mathbf{R u C}_{\mathbf{1}}$ and $\mathbf{R u T}_{\mathbf{1}}$ with the highest 2PA enhancement (up to $118 \%$ ), it is clearly demonstrated that the further addition of $\mathbf{F}$ ligands has no effect on the 2PA performance. By contrast to the other ligands, the increase of interchromophoric interactions emerging from the close proximity of $\mathbf{F}$ within $\mathbf{R u F}_{\mathbf{2}}$ or $\mathbf{R u F}_{\mathbf{3}}$ paradoxically generates 'anti-cooperative' effects $^{16}$ which collapse the 2PA performance. These detrimental interactions should originate from the crowded and rigid character of $\mathbf{F}$ which drastically limits the fine orientation and the relative positioning of the polar branches within the complex. With this respect, there is no doubt that $\mathbf{T}$ appears as an optimal prototype which displays the good compromise between large dipole moment change and reasonable flexibility within a sterically constrained architecture. Such structural conditions undoubtedly establish a guideline for the future design of new multipolar metal-complexes allowing a real gain in term of 2PA performance.

\section{Notes and references}

1. G. S. He, L.-S. Tan, Q. Zheng and P. N. Prasad, Chem. Rev., 2008, 108, 1245-1330.

2. C. N. LaFratta, J. T. Fourkas, T. Baldacchini and R. A. Farrer, Angew. Chem. Int. Ed., 2007, 46, 6238-6258.

3. C. C. Corredor, Z.-L. Huang, K. D. Belfield, A. R. Morales and M. V. Bondar, Chem. Mater., 2007, 19, 5165-5173.

4. D. L. N. Kallepalli, A. M. Alshehri, D. T. Marquez, L. Andrzejewski, J. C. Scaiano and R. Bhardwaj, Sci. Rep., 2016, 6, 26163.

5. Q. Zhang, X. Lu, H. Wang, X. Tian, A. Wang, H. Zhou, J. Wu and Y. Tian, Chem. Commun., 2018, 54, 3771-3774.

6. Z. Feng, D. Li, M. Zhang, T. Shao, Y. Shen, X. Tian, Q. Zhang, S. Li, J. Wu and Y. Tian, Chem. Sci., 2019, 10, 7228-7232.

7. A. Picot, A. D'Aléo, P. L. Baldeck, A. Grichine, A. Duperray, C. Andraud and O. Maury, J. Am. Chem. Soc., 2008, 130, 15321533.

8. F. Bolze, S. Jenni, A. Sour and V. Heitz, Chem. Commun., 2017, 53, 12857-12877.

9. M. Pawlicki, H. A. Collins, R. G. Denning and H. L. Anderson, Angew. Chem. Int. Ed., 2009, 48, 3244-3266.

10. O. Maury, L. Viau, K. Sénéchal, B. Corre, J.-P. Guégan, T. Renouard, I. Ledoux, J. Zyss and H. Le Bozec, Chem. Eur. J., 2004, 10, 4454-4466.

11. C. Feuvrie, O. Maury, H. Le Bozec, I. Ledoux, J. P. Morrall, G. T. Dalton, M. Samoc and M. G. Humphrey, J. Phys. Chem. A, 2007, 111, 8980-8985.

12. H. Le Bozec, T. Renouard, M. Bourgault, C. Dhenaut, S. Brasselet, I. Ledoux and J. Zyss, Synth. Met., 2001, 124, 185189.

13. P. Savel, H. Akdas-Kilig, J.-P. Malval, A. Spangenberg, T. Roisnel and J.-L. Fillaut, J. Mater. Chem. C, 2014, 2, 295-305.

14. G. Lemercier, M. Four and S. Chevreux, Coord. Chem. Rev., 2018, 368, 1-12.

15. F. Terenziani, C. Katan, E. Badaeva, S. Tretiak and M. BlanchardDesce, Adv. Mater., 2008, 20, 4641-4678.

16. F. Terenziani, V. Parthasarathy, A. Pla-Quintana, T. Maishal, A.M. Caminade, J.-P. Majoral and M. Blanchard-Desce, Angew. Chem. Int. Ed., 2009, 48, 8691-8694.

17. E. Collini, Phys. Chem. Chem. Phys., 2012, 14, 3725-3736.

18. X.-B. Zhang, J.-K. Feng and A.-M. Ren, J. Phys. Chem. A, 2007, 111, 1328-1338.

19. O. Yurchenko, D. Freytag, L. zur Borg, R. Zentel, J. Heinze and S. Ludwigs, J. Phys. Chem. B, 2012, 116, 30-39.

20. A. Kapturkiewicz, J. Herbich, J. Karpiuk and J. Nowacki, J. Phys. Chem. A, 1997, 101, 2332-2344.

21. N. Mataga, Y. Kaifu and M. Koizumi, Bull. Chem. Soc. Jpn., 1955, 28, 690-691.

22. E. Lippert, Z. Naturforsch., 1955, 10a, 541-545.

23. A. Juris, V. Balzani, F. Barigelletti, S. Campagna, P. Belser and A. von Zelewsky, Coord. Chem. Rev., 1988, 84, 85-277.

24. H. Song, X. Wang, W. Yang, G. He, Z. Kuang, Y. Li, A. Xia, Y.-W. Zhong and F. Kong, Chem. Phys. Lett., 2017, 683, 322-328.

25. D. Bruce, J. McCall and M. M. Richter, Analyst, 2002, 127, 125128.

26. S. Das, A. Nag, D. Goswami and P. K. Bharadwaj, J. Am. Chem. Soc., 2005, 128, 402-403.

27. M. G. Kuzyk, J. Chem. Phys., 2003, 119, 8327-8334.

28. J. P. Moreno and M. G. Kuzyk, J. Chem. Phys., 2005, 123, 194101-194113. 